\title{
Multi-Objective Approach to TCSC and DG Coordination under Contingency in an Integrated Transmission and Distribution Networks
}

This paper was downloaded from TechRxiv (https://www.techrxiv.org).

\section{LICENSE}

CC BY 4.0

SUBMISSION DATE / POSTED DATE

20-01-2022 / 27-01-2022

\section{CITATION}

Ahmad, Abubakar Sadiq; Buhari, Muhammad; Ambafi, James Garba; Adamu, Sunusi Sani; Ndubuka, Nwohu Mark (2022): Multi-Objective Approach to TCSC and DG Coordination under Contingency in an Integrated Transmission and Distribution Networks. TechRxiv. Preprint. https://doi.org/10.36227/techrxiv.18786500.v1

$\mathrm{DOI}$ 


\title{
Multi-Objective Approach to TCSC and DG Coordination under Contingency in an Integrated Transmission and Distribution Networks
}

\author{
Abubakar SadiqAhmad, Member, IEEE, Muhammad Buhari, Senior Member, IEEE, James Garba Ambafi, \\ Sunusi Sani Adamu, Member, IEEE and Mark Ndubuka Nwohu
}

\begin{abstract}
Flexible AC Transmission System (FACTS) are deployed by Transmission System Operators (TSO) to manage congestion while meeting technical and multilateral supply commitments. Another issue is the de-carbonizing of the power supply framework by increasing penetration of Distributed Generation (DG) often at distribution network. However, separately planned FACTS and DG units by system operators (TSO and DSO) can worsen power systems performance in the presence of load growth. Therefore, this paper demonstrates the coordination of TCSC and DG through a multi-objective Particle Swarm Optimization (MOPSO) technique at the instance of $T S O-D S O$ coordination scheme, to improve transfer capability, power loss and voltage deviation in an integrated transmission and distribution network (iT \& DN). Two models of DG were coordinated with TCSC under normal and contingency cases. Results indicate that while ATC improvement for various transactions was achieved with TCSC, additional power losses incurred were further reduced with DG deployment in coordination with TCSC. Furthermore, the Pareto front, which establishes the correlation between objectives shows a diving parabola that is partly nonlinear. Also, the $T C S C-D G_{P Q}$ provide superior ATC and power losses compared with $T C S C-D G_{P V}$. Again, under $(N-1)$ contingencies, the $T C S C-D G_{P Q}$ provides improved ATC compared with other contingency cases under TCSC only.
\end{abstract}

Index Terms-DG, Contingency, Coordination, MultiObjective, Transfer Capability, TCSC.

\section{INTRODUCTION}

G LOBALLY, the dependence of human activities on electrical energy is rising steadily, which led to exponential growth in the demand for electricity under deregulation. However the load centres, often located far from the generation sources which necessitate bulk power transfers involving multilateral transactions remain a common feature of a deregulated electricity market. The competitive framework of deregulation involving multilateral bids with increased demand causes tie lines to operate closer to and sometimes above transfer limits - thermal, voltage and stability [1]-[3]. Operating tie lines at their limits have caused network congestion, huge losses, poor voltage profile, and instability [4], with cascading impacts on the low voltage Distribution Networks (DN) [5].

In order to manage network operational performance and stability, the Transmission System Operators (TSO) must relieve congestion while meeting technical and multilateral

This paper was produced by the IEEE Publication Technology Group. They are in Piscataway, NJ.

Manuscript received January xx, 2022; revised xxxxx xx, 2022. supply commitments. Among the solutions adopted to enhance the static and dynamic performance of power systems, the Flexible AC Transmission System (FACTS) devices are favourable features of the Transmission Networks (TN) [6][8]. Different FACTS were deployed for Available Transfer Capability [9]-[11], voltage stability [12], power losses [13], [14], dynamic stability [15], and congestion management [4], [6], [8]. A cost effective series FACTS family which modifies the effective line reactance is the Thyristor Controlled Series Compensator (TCSC) [16]. In complementing FACTS' deployment, the recent drive to decarbonize the power supply framework witnessed increased deployment and utilization of Renewable Energy (RE) based Distributed Generation (DG), at the DN [17]. Although the increased penetration of DG reduces environmental impact, the grid-connected mode presents complexities if not properly planned [18]. Thus, increased penetration of DG raise concerns about stable and reliable operation due to intermittency in irradiance for power generation. Other issues of DG penetration, such as low fault ride-through, high fault current, and low power quality, may get worsen by FACTS' control operations [19], [20].

The Literature is replete with the benefits of FACTS and DG in power systems: enhanced voltage stability, minimising power loss, improving transfer capability, and power system's management close to operating points [21]. FACTS also provide economic benefits in cost savings from loss and fuel cost minimization [22]. However, the distinction between Transmission and Distribution Network (T \& DN) planning, and by extension FACTS and DG, translate to the uncoordinated system operators, which worsen power systems performance in the presence of demand growth [9], is scarcely addressed. Therefore, discordance of DG planning ignoring active DN due to high DG penetration has been demonstrated to have adverse effects in [5], while the ability of TCSC to dampen oscillation is demonstrated in [23]. Accordingly, TSO and DSO coordination is critical to optimize the benefits of FACTS and DG planning. The basic concern in TSO-DSO coordination is the ability of DSO to deploy its resources, to provide services to TSO [24]. Moreover, the TSO - DSO coordination environment must depict the features of T \& DN. Consequently, the model of an integrated Transmission and Distribution Network (iT \& DN) is necessary, combining both the high and medium voltage sections [25]-[27]. Generally, services provided between TSO and DSO can be described in terms of cost functions of FACTS and DG [21]. 


\section{LiterATURE REVIEW}

Structural changes in modern power systems and manifestation of active DN are largely attributed to penetration of DG units. Consequently, separate planning of $\mathrm{T} \& \mathrm{DN}$ are no longer favourable. Economic dispatch, a major issue in planning and operation, requires coordinating resources available to the system operators. While TN planning concerns periodical location of new infrastructures such as FACTS; to meet the demand growth, DN planning targets the optimal location and sizes of the substations and DGs. Therefore, the modern framework enables DSO to provide services in coordination with TSOs for an inclusive benefit [28]. Thus, the need for coordination between TSO and DSO from operational and planning perspectives. Accordingly, [29] presented a hierarchical framework to optimise TSO and DSO coordination simultaneously.

The work by [1] acknowledged that high penetration of DG causes reactive power demand, voltage instability, congestion, harmonics, power losses and other imbalances. Therefore, to avoid system-wide impacts, installing compensator such as TCSC, SVC, and STATCOM is necessary, to mitigates the impacts of DG. In [2], the optimal placement of TCSC and DG is presented to manage congestion from load growth and line outages. Based on OPF formulation, the impacts of DG on FACTS and vice-versa and lack of distinction between T \& DN were ignored. Similarly, planning of multiple DG and TCSC for power loss reduction is presented by [14]. In addition to a single objective, it was limited to DN. Furthermore, the coordination of DG, Shunt Capacitors (SC) and Static Var Compensators (SVC) were presented in [9], [13]. While [13] compares $D G-S V C$ with $D G-S C$, only power loss reduction is considered. In addition to power loss, [9] discussed the $S V C-D G$ coordination to enhance Available Transfer Capability (ATC) in a multi-objective approach. However, both ignored the distinction between TSO and DSO. To mitigate the uncertainty caused by DG, [22] combined the reactive power, transmission expansion, and TCSC planning to minimize investment costs of transmission lines, reactive power sources, and TCSC devices.

In order to improve the technical and economic indices, a Multi-Objective Particle Swarm Optimization (MOPSO) is utilized to optimally place TCSC in [30]. While the work ignores DG, one of the Pareto-optimal solutions is selected using the fuzzy decision method as the best compromise. Also, a multiobjective approach to planning of FACTS and DG is presented in [21]. The objectives mainly constitute cost of FACTS and DG as well as loss discount. In addition to the none optimal solution due to the analytical approach, there is no distinction between TSO and DSO of the modern competitive framework. Similarly, a multi-objective biogeography-based optimization (MOBBO) algorithm is used in [31] to optimally plan Static Synchronous Series Compensator (SSSC) in the wind integrated network.

Therefore, from the survey, separate planning of TCSC and DG were targeted at the $\mathrm{T} \& \mathrm{DN}$ respectively, to improve various objectives. However, the planning of TCSC and DG often has ignored the imminent impacts of TCSC control operations on DG and vice versa. Furthermore, power system operations involve monitoring multiple performance indices, hence multi-objective problem formulation. Consequently, this paper demonstrates the coordination of TCSC and DG to improve ATC, power loss and voltage deviation in an iT \& DN using muti-objective approach.

\section{TCSC - DG COORDINATION APPROACH}

The consideration of DN to facilitate effective provision of services to the $\mathrm{TN}$ is an important factor in TSO - DSO planning [32]. The TCSC $-D G$ planning scenario depicts the TSO managed model, a fully centralized dispatch model, accounting for T \& DN constraints [26], [32]. In the TCSC$D G$ coordination model depicted in Fig. 1 and operated by the TSO, resources available to both transmission and distribution levels are deployed and managed by the TSO in a coordinated manner for inclusive benefit.

\section{Multi-Objective PSO (MOPSO)}

Planning studies often target multiple objectives, which sometimes are contradictory. Due to multi-objectives, the search space is not always well defined, hence the need for a Multi-Objective Optimization (MOO), which has no absolute global best, but set of non-dominated solutions. In MOO, the objectives may not have a direct correlation. A general minimization formulation is expressed in equation (1), subject to equality and inequality constraints of equations (2) and (3).

$$
\begin{gathered}
\operatorname{minimize} \vec{f}(x, \lambda)=\left[f_{1}(x, \lambda), f_{2}(x, \lambda) \ldots f_{m}(x, \lambda)\right] \\
f(x, \lambda)=0 \\
X_{i}^{\min }(x, \lambda) \leq X_{i}(x, \lambda) \leq X_{i}^{\max }(x, \lambda)
\end{gathered}
$$

In equations (1) to (3), $x$ and $\lambda$ are vector of state and control variables respectively. The Pareto optimal approach is applied to the problem of equation (1), described by dominance model. For a problem having $m$ objectives, a solution $\left(x_{i}, \lambda_{i}\right)$ dominates other solution $\left(x_{j}, \lambda_{j}\right)$, if $\left(x_{i}, \lambda_{i}\right)$ is better than $\left(x_{j}, \lambda_{j}\right)$ for at least one objective $\vec{f}_{i}(x, \lambda)$ and is not worse for any other $\overrightarrow{f_{j}}(x, \lambda)$ as described in equation (4). Where $j=1,2 \ldots m$ and $j \neq i$. The symbol $\succ$ represents the domination concept. In a non-dominated pair, an improvement in objective $\overrightarrow{f_{i}}(x, \lambda)$ can cause the deterioration of other objectives [31].

$$
\left.\begin{array}{c}
\overrightarrow{f_{i}}\left(x_{1}, \lambda_{1}\right)<\overrightarrow{f_{i}}\left(x_{2}, \lambda_{2}\right) \\
\quad \text { and } \\
\overrightarrow{f_{j}}\left(x_{1}, \lambda_{1}\right) \leq \overrightarrow{f_{j}}\left(x_{2}, \lambda_{2}\right)
\end{array}\right\} \Rightarrow\left(x_{1}, \lambda_{1}\right) \succ\left(x_{2}, \lambda_{2}\right)
$$

\section{A. ATC-Objective using Continuation Power Flow (CPF)}

MOO can exist in two fronts, involving both minimization and maximization, hence the need to transform to the same front. At the maximum power transfer limit imposed by thermal, voltage, and generator reactive power [10], the ATC evaluate to equation (5).

$$
\operatorname{Max} .\left\{\sum_{i \in \sin k} P_{L}^{i}\left(\lambda=\lambda_{\text {lim }}\right)-\sum_{i \in \sin k} P_{L}^{i}(\lambda=0)\right\}
$$




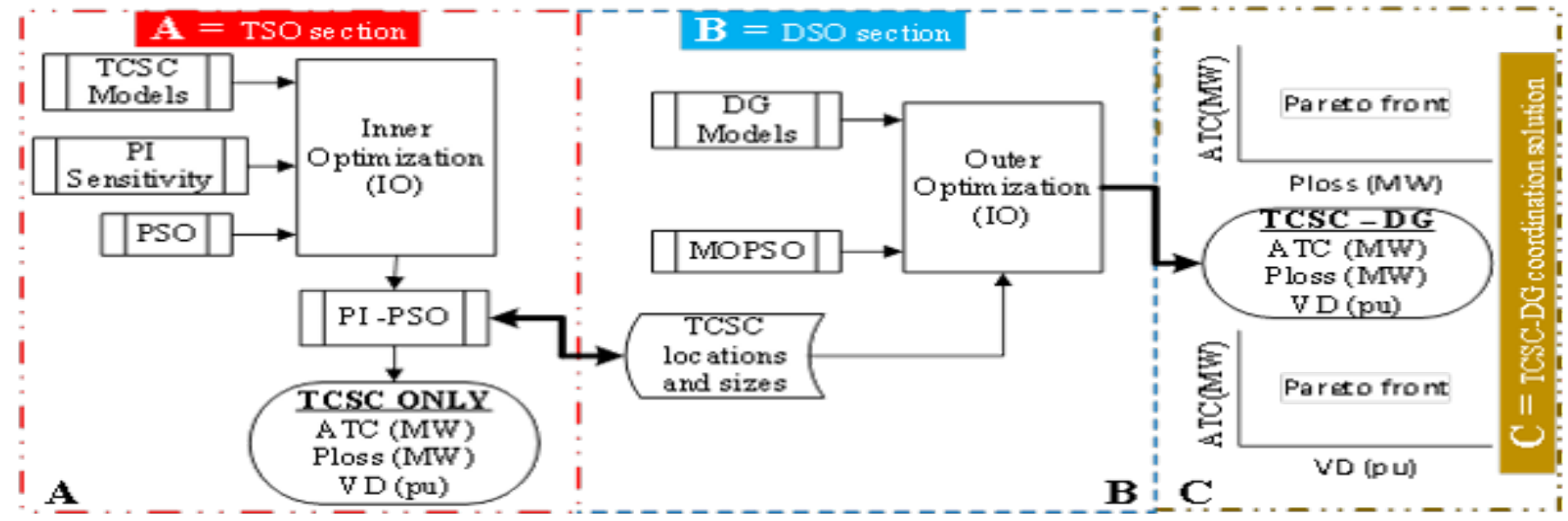

Fig. 1. TCSC $-D G$ Coordination Model.

Negating the ATC term of equation (5), transform the problem formulation to minimisation front.

\section{B. Power loss-Objective}

Equation (6) expresses the real power loss of an integrated power system comprising the T \& DN losses. Where $g_{k}$ is the conductance of transmission line. $V_{i}, V_{j}, \delta_{i}, \delta_{i}$ are the voltage magnitudes and angles at buses/nodes $i$ and $j$ respectively, $n l$ is the number of lines in the network.

$$
\begin{array}{r}
P_{\text {loss }}^{n e t}=P_{\text {loss }}^{T S O}+P_{\text {loss }}^{D S O} \\
P_{\text {loss }}^{n e t}=\sum_{k=1}^{n l} g_{k}\left(V_{i}^{2}+V_{j}^{2}-2 V_{i} V_{j} \cos \left(\delta_{i}-\delta_{j}\right)\right)
\end{array}
$$

\section{Voltage Deviation-Objective}

For each bus/node, the deviation of voltage magnitudes away from 1p.u measures the quality of voltage at such bus/node. Thus, the absolute sum of voltage deviation of all bus/nodes in the network is taken as a measure of the network's overall quality of voltage supply expressed by equation (7).

$$
V_{D}^{n e t}=V_{D}^{T S O}+V_{D}^{D S O}=\sum_{i=1}^{n b}\left|1-V_{i}\right|
$$

Equation (8) describes the set of fitness vector $A T C, P_{\text {loss }}^{\text {net }}$ and $V_{D}^{\text {net }}$, for the TCSC-DG coordination using MOPSO.

$$
\vec{f}(x, \lambda)=\left\{\begin{array}{l}
-A T C \\
P_{\text {loss }}^{\text {net }}=P_{\text {loss }}^{T S O}+P_{\text {loss }}^{D S O} \\
V_{D}^{\text {net }}=V_{D}^{T S O}+V_{D}^{D S O}
\end{array}\right.
$$

\section{TCSC AND DG MODELLING}

\section{A. TCSC Power Injection Model (PIM)}

The pie equivalent model of a transmission line with TCSC $j x_{c}$ is given in Fig. 2. The equivalent line reactance with TCSC is given by the equation (9), while the active and reactive power flows with TCSC are expressed by the equations (10) - (15).

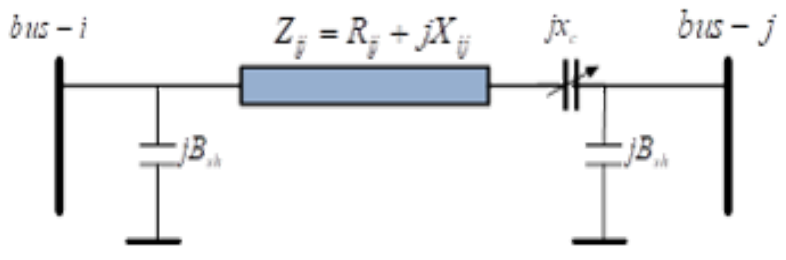

Fig. 2. Transmission line Model with TCSC.

$$
\begin{gathered}
X_{i j}^{e q u}=X_{i j}+X_{c} \\
P_{i j}=V_{i}^{2} G_{i j}^{\prime}-V_{i} V_{j}\left(G_{i j}^{\prime} \cos \delta_{i j}+B_{i j}^{\prime} \sin \delta_{i j}\right) \\
Q_{i j}=-V_{i}^{2}\left(B_{i j}^{\prime}+B_{s h}\right)- \\
V_{i} V_{j}\left(G_{i j}^{\prime} \sin \delta_{i j}-B_{i j}^{\prime} \cos \delta_{i j}\right) \\
P_{j i}=V_{j}^{2} G_{i j}^{\prime}-V_{j} V_{i}\left(G_{i j}^{\prime} \cos \delta_{i j}-B_{i j}^{\prime} \sin \delta_{i j}\right) \\
Q_{j i}=-V_{j}^{2}\left(B_{i j}^{\prime}+B_{s h}\right)+ \\
V_{j} V_{i}\left(G_{i j}^{\prime} \sin \delta_{i j}+B_{i j}^{\prime} \cos \delta_{i j}\right)
\end{gathered}
$$

where,

$$
\begin{aligned}
G_{i j}^{\prime} & =\frac{r_{i j}}{r_{i j}^{2}+\left(x_{i j}-x_{c}\right)^{2}} \\
B_{i j}^{\prime} & =\frac{-\left(x_{i j}-x_{c}\right)}{r_{i j}^{2}+\left(x_{i j}-x_{c}\right)^{2}}
\end{aligned}
$$

Consequently, from Fig. 2, using the Power Injection Model (PIM), the effect of TCSC's series reactance on active power flow are represented by equivalent power injections at receiving and sending end of the line without TCSC [33], as shown in Fig. 3. Equations (16) and (17) give the real power injections at both ends of Fig. 3, while equations (18) and (19) give the change in conductance and susceptance, respectively.

$$
\begin{aligned}
& P_{i c}=V_{i}^{2} \Delta G_{i j}-V_{i} V_{j}\left(\Delta G_{i j} \cos \delta_{i j}+\Delta B_{i j} \sin \delta_{i j}\right) \\
& P_{j c}=V_{j}^{2} \Delta G_{i j}-V_{j} V_{i}\left(\Delta G_{i j} \cos \delta_{i j}-\Delta B_{i j} \sin \delta_{i j}\right)
\end{aligned}
$$




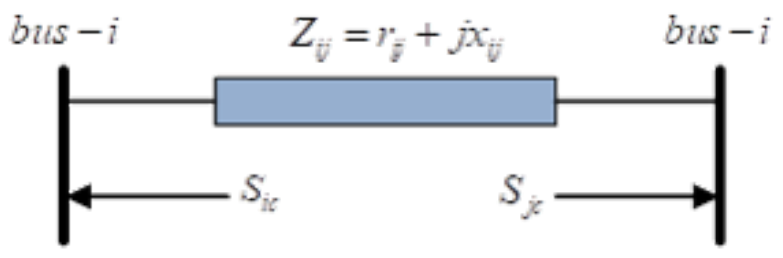

Fig. 3. Power Injection Model of TCSC.

$$
\begin{aligned}
\Delta G_{i j} & =\frac{x_{c} r_{i j}\left(x_{c}-2 r_{i j}\right)}{\left(r_{i j}^{2}+x_{i j}^{2}\right)\left(r_{i j}^{2}+\left(x_{i j}^{2}-x_{c}\right)^{2}\right)} \\
\Delta B_{i j} & =\frac{-x_{c}\left(r_{i j}^{2}-x_{i j}^{2}+x_{c} x_{i j}\right)}{\left(r_{i j}^{2}+x_{i j}^{2}\right)\left(r_{i j}^{2}+\left(x_{i j}^{2}-x_{c}\right)^{2}\right)}
\end{aligned}
$$

\section{B. DG Modelling}

Based on DG's ability to inject real and reactive power [34], [35], two DG models are implemented [36]-[39].

1) PV Model: DG supplies only real power.

2) PQ Model: DG supplies real and reactive power.

DGs are modelled as negative load [36] when the dynamics and fast transients associated with converter-based DG are neglected. Accordingly, if $P_{l i}$ and $Q_{l i}$ represent the real and reactive load at the $i^{\text {th }}$ node of a DN, equations (20) and (21) describe the new loads ( $P_{n l i}, Q_{n l i}$ ) after DG integration; where $\gamma_{d g}^{p}$ and $\gamma_{d g}^{q}$ are real and reactive power injections from DG units.

$$
\begin{gathered}
P_{n l i}=P_{l i}-\gamma_{d g}^{p} \\
Q_{n l i}=Q_{l i}-\gamma_{d g}^{q}
\end{gathered}
$$

Equations (20) and (21) imply that DG units replace a certain amount of load demand at the said DN's node and is subject to the power balance equations (22) and (23).

$$
\begin{gathered}
P_{G}^{i}-P_{L}^{i}-P_{i n j}^{i}=0 \\
Q_{G}^{i}-Q_{L}^{i}-Q_{i n j}^{i}=0
\end{gathered}
$$

The power injections $P_{i n j}^{i}$ and $Q_{i n j}^{i}$ is described by equations (24) and (25) respectively; where $P_{G}^{i}, Q_{G}^{i}, P_{L}^{i}, Q_{L}^{i}$ are real and reactive generation and load at the $i^{t h}$ node.

$$
\begin{aligned}
P_{i n j}^{i} & =\sum_{j=1}^{n} V_{i} V_{j} Y_{i j} \cos \left(\delta_{i}-\delta_{j}-\theta_{i j}\right) \\
Q_{i n j}^{i} & =\sum_{j=1}^{n} V_{i} V_{j} Y_{i j} \cos \left(\delta_{i}-\delta_{j}+\theta_{i j}\right)
\end{aligned}
$$

DG penetration level stipulates the limit of real or reactive power supply from DG, and the equation (26) defines penetration level [34].

$$
\sum_{i=1}^{n d g} P Q_{d g}^{i} \leq \mu \sum_{j \in P Q_{\text {load }}} P Q_{\text {load }}^{j}
$$

In the equation (26), the total real or reactive power injected by $\mathrm{DG}$ is a percentage of the DN real or reactive power demand; hence, the penetration level is $\mu$. The inequality constraint described by equations (3), limits the maximum real and reactive from DG to $75 \%$ of $P Q_{\text {load }}$ load in DN [40]-[42] as described by equation (27) and (28).

$$
\begin{gathered}
0 \leq \gamma_{d g}^{p} \leq 0.75 P_{\text {load }}^{d n} \\
-0.75 Q_{\text {load }}^{d n} \leq \gamma_{d g}^{q} \leq 0.75 Q_{\text {load }}^{d n}
\end{gathered}
$$

\section{Reduced Search Space}

Since power flows and overloads are major constraints to ATC [43], the sensitivity of real power flow to TCSC's reactance is used to obtain the list of candidate lines for TCSC location [44].

\section{A. Real Power Flow Sensitivity}

The sensitivity of real power flow in a line where TCSC is located can be expressed in terms of partial derivatives of the power injection in terms of equations (16) and (17), as expressed by equations (29) and (30), respectively [33].

$$
\begin{array}{r}
\left.\frac{\partial P_{i}}{\partial X_{k}}\right|_{x_{k}=0}=\left.\frac{\partial P_{i c}}{\partial X_{k}}\right|_{\substack{x_{k}=0 \\
(29 \mathrm{a})}}= \\
\left.\left(V_{i}^{2}-V_{i} V_{j} \cos \delta_{i j}\right) \frac{\partial \Delta G_{i j}}{\partial X_{k}}\right|_{x_{k}=0}-\left.\left(V_{i} V_{j} \sin \delta_{i j}\right) \frac{\partial \Delta B_{i j}}{\partial X_{k}}\right|_{\substack{x_{k}=0 \\
(29 \mathrm{~b})}} \\
\left.\frac{\partial P_{j}}{\partial X_{k}}\right|_{x_{k}=0}=\left.\frac{\partial P_{j c}}{\partial X_{k}}\right|_{x_{k}=0}= \\
(30 \mathrm{a}) \\
\left.\left(V_{j}^{2}-V_{i} V_{j} \cos \delta_{i j}\right) \frac{\partial \Delta G_{i j}}{\partial X_{k}}\right|_{x_{k}=0}+\left.\left(V_{i} V_{j} \sin \delta_{i j}\right) \frac{\partial \Delta B_{i j}}{\partial X_{k}}\right|_{\substack{x_{k}=0 \\
(30 \mathrm{~b})}}= \\
\text { where }\left.\frac{\partial \Delta G_{i j}}{\partial X_{k}}\right|_{x_{k}=0}=2 G_{i j} B_{i j} \text { and }\left.\frac{\partial \Delta B_{i j}}{\partial X_{k}}\right|_{x_{k}=0}=B_{i j}^{2}-G_{i j}^{2}
\end{array}
$$

\section{B. Hybrid Real Power Flow Sensitivity and PSO (PI-PSO)}

Consequently, with the reduced search space constituting the candidate locations obtained by real power flow sensitivity, PSO is deploy to locate and size TCSC for ATC enhancement. The complete documentation of the hybrid real power flow sensitivity and PSO is given in [10].

\section{Synthetic Test Network (IT \& DN)}

The power system test network is carefully selected to model an integrated Transmission and Distribution Network (iT \& DN). The high voltage transmission section is the Western System Coordinating Council network (WSCC) at a nominal of $230 \mathrm{kV}$, while the IEEE 16 nodes form the distribution section at a nominal of $23 \mathrm{kV}$. Fig. 4 depicts the topology of the iT \& DN [5]. Fig. 4a shows the one-line diagram of iT \& DN illustrating the point of common coupling between transmission and distribution sections, while Fig. $4 \mathrm{~b}$ gives the entire topology of the modified test network with part of the loads at buses 5, 6 and 8 of the transmission section replaced by IEEE 16 nodes distribution network. 


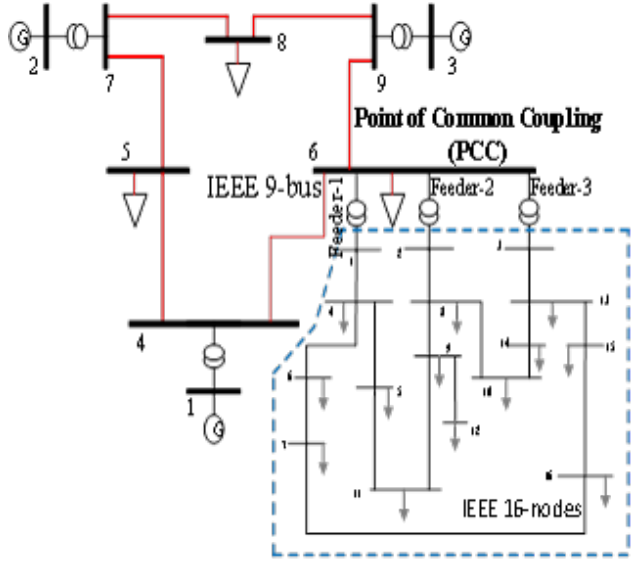

(a)

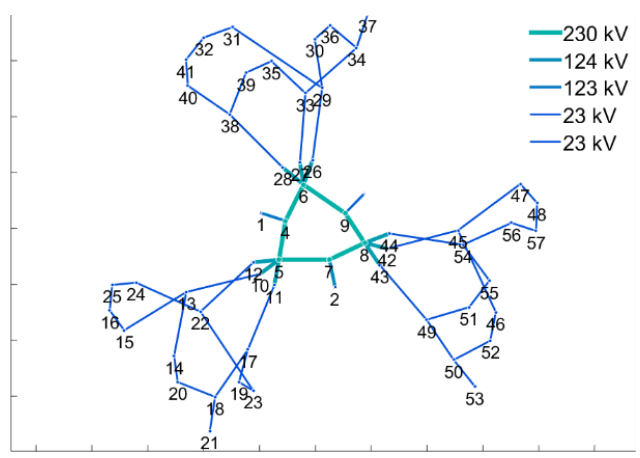

(b)

Fig. 4. Topology of the iT \& DN. (a) One-line diagram of iT \& DN. (b) Case Entire topology of iT \& DN.

\section{A. Single Line $(N-1)$ Outage Contingency}

A composite severity index for transmission line outage, which is a function of apparent power flow and voltage limit violations, is adopted to measure the impacts of a given single line $(N-1)$ outage contingency. Equation (31) describes the performance index of the composite $m^{t h}$ line outage contingency $P I_{S-V}^{m}(N-1)$.

$$
P I_{S-V}^{m}(N-1)=f\left(f_{p}(x), f_{v}(x)\right)
$$

In equation (31) $x$ is a vector of the state variable (voltage magnitude and angle). $f_{p}(x)$ is the apparent power flow performance index defined by equation (32), where $\omega_{m}$ is a real nonnegative weight coefficient that reflects the importance of the line, $P_{l m}$ is active power flow, $P_{l m}^{\text {rated }}$ is maximum allowable active power flow through the line, $n$ is integer exponent.

$$
f_{p}(x)=\sum_{m=1}^{N l} \frac{w_{m}}{2 n}\left(\frac{P_{l m}}{P_{l m}^{\text {rated }}}\right)^{2 n}
$$

Equations (33) and (34) give two variants of the voltage index measures of line outage performance index $f_{p}(x)$.

$$
\begin{gathered}
f_{v}(x)_{1}=\sum_{i=1}^{n b} \frac{\omega_{i}}{2} \frac{\Delta V_{i}}{\Delta V_{i}^{\lim }} \\
f_{v}(x)_{2}=\sum_{i \in V_{v i o}} \frac{\left|V_{i}-V_{i}^{\lim }\right|}{V_{i}^{\lim }}
\end{gathered}
$$

From equations (33) and (34), $n b$ and $\omega_{i}$ are the number of buses and weight coefficient respectively, while equations (35) and (36) define the terms $\Delta V_{i}, \Delta V_{i}^{\text {lim }}$ and $V_{i}^{\text {lim }}$ of equations (33) and (34).

$$
\begin{aligned}
& \left.\begin{array}{l}
\Delta V_{i}=V_{i}-V_{i}^{s p} \\
\Delta V_{i}^{\lim }=0.5 \times\left(V_{i}^{\max }-V_{i}^{\min }\right)
\end{array}\right\} \\
& V_{i}^{\lim }= \begin{cases}V_{i}^{\max } & \text { if } V_{i}>V_{i}^{\max } \\
V_{i}^{\min } & \text { if } V_{i}<V_{i}^{\min }\end{cases}
\end{aligned}
$$

where $V_{i}$ and $V_{i}^{s p}$ are the post and pre contingency voltage magnitude at the $i^{\text {th }}$ bus, $V_{i}^{\min }$ and $V_{i}^{\max }$ are upper and lower voltage limits. Also, in equation (34) $V_{\text {vio }}$ defines the set of all buses with post contingency voltage violation. The equation (37) gives the simplified form of equation (31) with the two voltage variant, respectively. In Fig. 4a, the outage of a transformer branch that causes a generator outage are excluded.

$P I_{S-V}^{m}(N-1)=\left\{\begin{array}{l}\sum_{m=1}^{N l} \frac{w_{m}}{2 n}\left(\frac{S_{l m}}{S_{l m}^{\text {rated }}}\right)^{2 n}+\sum_{i=1}^{n b} \frac{\omega_{i}}{2} \frac{\Delta V_{i}}{\Delta V_{i}^{\lim }} \\ \text { OR } \\ \sum_{m=1}^{N l} \frac{w_{m}}{2 n}\left(\frac{S_{l m}}{S_{l m}^{\text {rated }}}\right)^{2 n}+\sum_{i \in V_{\text {vio }}} \frac{\left|V_{i}-V_{i}^{\lim }\right|}{V_{i}^{\lim }}\end{array}\right.$

\section{B. Implementation}

The proposed $T C S C-D G$ coordination approach is implemented within MATLAB/MATPOWER environment [10]. Data exchange is between MATPOWER, which evaluate load flow and CPF, and MATLAB implementation of MOPSO. Table I gives PSO and MOPSO parameters.

TABLE I

PSO AND MOPSO PARAMTERS

\begin{tabular}{|c||c||c|}
\hline Parameters & PSO & MOPSO \\
\hline$\omega_{o}$ & 0.9 & 0.5 \\
\hline$\omega_{\text {damp }}$ & - & 0.99 \\
\hline$\omega_{i t}$ & $=0.1 * \frac{i t-1}{M a x_{\text {_ } i t-1}}$ & $=\omega_{0} * 0.99$ \\
\hline$C_{1}$ & 1.5 & 1.0 \\
\hline$C_{2}$ & $4-C_{1}$ & 2 \\
\hline Max $x_{I t}$ & 150 & 150 \\
\hline Swarm size $_{\text {Repositorty }}$ & 9 & 200 \\
\hline Grids per Dim. & - & 100 \\
\hline Inf. rate $(\alpha)$ & - & 7 \\
\hline Lead. Sel.Pre. $(\beta)$ & - & 0.1 \\
\hline Del. Sel. Pre. $(\gamma)$ & - & 2 \\
\hline Mutation Rate $(m u)$ & - & 2 \\
\hline
\end{tabular}

\section{RESUlT AND DiscusSiON}

The various power transfer directions [10], are described in Table II. The transfer direction comprises both bilateral and 
multilateral transactions. The $2^{\text {nd }}$ and $3^{\text {rd }}$ column of Table II outline the source and sink buses corresponding to each transaction. Additionally, the base case multiple objectives comprising the ATC, power losses and voltage deviation of the test network (iT \& DN) are also shown in Table II. From Table II, the binding limitation to each transaction is specific to transfer direction, which is either branch apparent power flows for $\mathrm{T} 1$ to $\mathrm{T} 10$ or bus voltage constraints in the case of T11 to T13.

Using $P I-P S O$, the active power loss and voltage deviation corresponding to the enhanced ATC values with TCSC for transactions T1 to T10 are given in Table III. The results in Table III are obtained such that the percentage compensation for TCSC is bounded within $-0.2 \leq X_{T C S C} \leq 0.8$

A comparison of the results of these objectives in Table II and Table III is depicted in Fig. 5. Observed that while ATC enhancement with TCSC was recorded, there are corresponding active power losses resulting from additional power flows due to bilateral and multilateral transactions. Also, the voltage profile resulting from the transactions shows further deviation from the base case conditions. Hence, the need for coordinated approach between TSO and DSO, thereby ensuring better performance (measured by the objectives) of the iT \& DN.

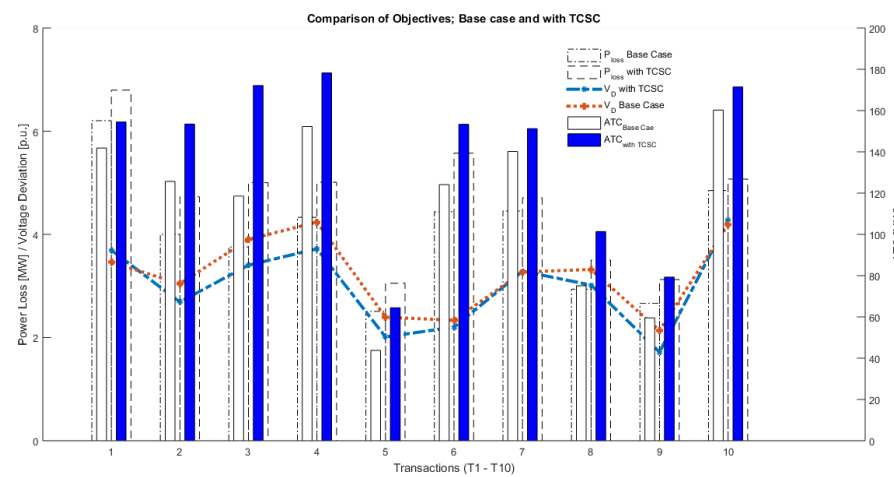

Fig. 5. Comparison of Objectives.

Accordingly, the TCSC - DG coordination model described in Fig. 1 is implemented. Thus, for different transactions of Table II, Fig. 6 shows the three dimensions (3D), non-dominated Pareto front of TCSC - DG coordination, for the optimisation of ATC, active power loss, and voltage deviation with both PV and PQ models of DG. As indicated in Table I, the Pareto front plots constitute the 100 members of the repository, which are the non-dominated solutions providing unique solutions among the competing objectives. It is observed that the 3D Pareto front in Figs. 6a to 6d indicates a diving parabolic like shape, which is partly nonlinear.

Furthermore, to gain a clearer insight into the relationships among the competing objectives, the slices of the 3D Pareto front plot illustrating the correlation between any two of the competing objectives will establish a unique understanding of the relationship between: ATC versus Ploss, ATC versus $V_{D}$ and Ploss versus $V_{D}$ respectively.

The slices of the Pareto front are obtained from the 3D plots of Figs.6a to 6d, thereby illustrating the correlation between

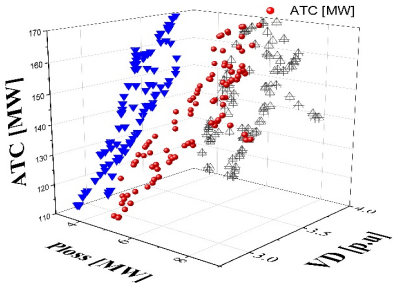

(a)

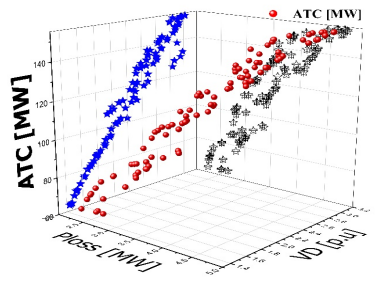

(c)

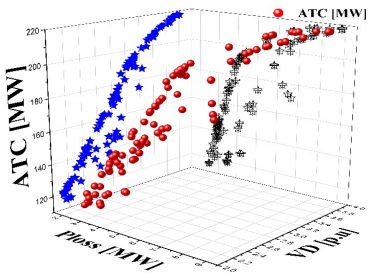

(b)

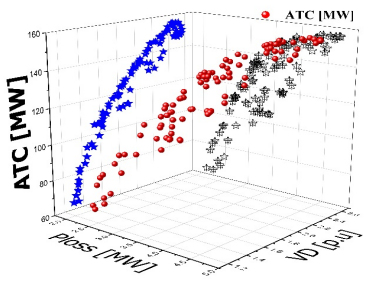

(d)
Fig. 6. Pareto front Plot of T1 with TCSC-DG. (a) T1 under TCSC$D G_{P V}$ (b) T1 under $T C S C-D G_{P Q}$ (c) T2 under $T C S C-D G_{P V}$ (d) T2 under $T C S C-D G_{P Q}$.

any two objectives. For transactions $\mathrm{T} 1$ and $\mathrm{T} 3$, the Pareto plot slices of ATC against real power loss (Ploss) and ATC against voltage deviation $\left(V_{D}\right)$ are given in Fig.7 and Fig.8 respectively. It is worthy to state here that the Pareto plot slices between Ploss and $V_{D}$ depicts disorderliness and hence were not discussed further.

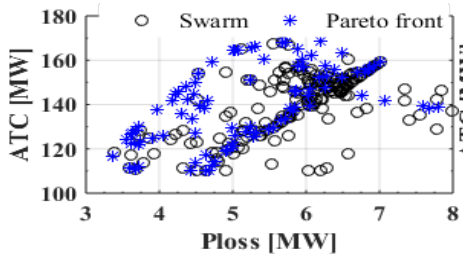

(a)

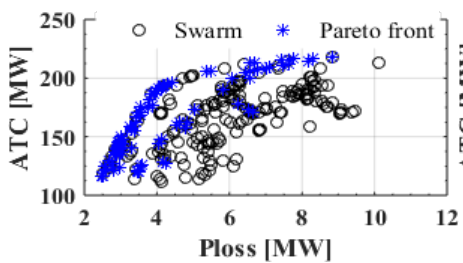

(c)

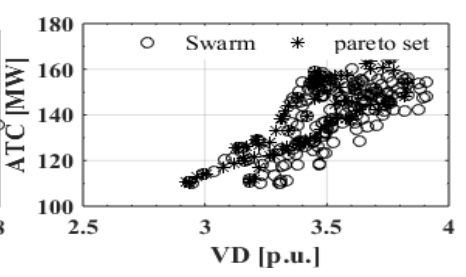

(b)

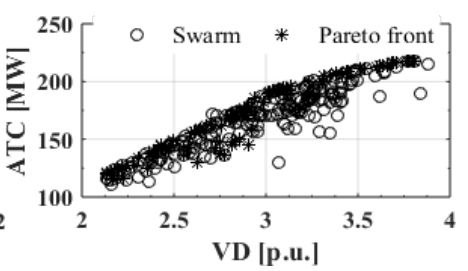

(d)
Fig. 7. Slices of Pareto plot for transaction $\mathrm{T} 1$ under $T C S C-D G$. (a) ATC versus $P_{l e s s}\left(T C S C-D G_{P V}\right)$ (b) ATC versus $V_{D}\left(T C S C-D G_{P V}\right)$ (c) ATC versus $P_{\text {loss }}\left(T C S C-D G_{P Q}\right)$ (d) ATC versus $V_{D}$

$$
\left(T C S C-D G_{P Q}\right)
$$

For the power transfer transaction illustrated in Fig.7 and Fig8, the sub-figures such as Figs. $7 \mathrm{a}$ and $7 \mathrm{~b}$ depict the Pareto front slices with $T C S C-D G_{P V}$ while Figs. 7c and $7 \mathrm{~d}$ depicts $T C S C-D G_{P Q}$ coordination. Similarly, subfigures Figs. 7a and 7c give the Pareto front slices for the correlation between ATC versus Ploss, whereas Figs. $7 \mathrm{~b}$ and $7 \mathrm{~d}$ gives the correlation between Pareto front of ATC versus 
TABLE II

Base Case ATC For VARIous TRANSACTIONS OF IT \& DN TEST NeTWORK

\begin{tabular}{|c|c|c|c|c|c|c|c|c|}
\hline \multirow{2}{*}{$\begin{array}{c}\text { Trans } \\
\text { ID }\end{array}$} & \multirow[t]{2}{*}{ Source } & \multirow[t]{2}{*}{ Sink } & \multirow{2}{*}{$\begin{array}{c}\text { Loading Factor } \\
\lambda_{\max }\end{array}$} & \multicolumn{2}{|c|}{ ATC } & \multirow{2}{*}{$\begin{array}{l}P_{\text {loss }} \\
{[\mathrm{MW}]}\end{array}$} & \multirow{2}{*}{$\begin{array}{c}V_{D} \\
\text { [p.u.] }\end{array}$} & \multirow[t]{2}{*}{ Limiting Elemen } \\
\hline & & & & [p.u.] & [MW] & & & \\
\hline T1 & 1,3 & 5 & 1.5761 & 1.41817 & 141.8172 & 6.2044 & 3.6935 & $3(5$ to 7$)$ \\
\hline T2 & 1,2 & 5,8 & 0.6620 & 1.25676 & 125.6763 & 3.9991 & 2.6895 & $5(7$ to 8$)$ \\
\hline T3 & $1,2,3$ & 5,6 & 0.5520 & 1.18561 & 118.5608 & 3.7575 & 3.4024 & $3(5$ to 7$)$ \\
\hline $\mathrm{T} 4$ & $1,2,3$ & 6,8 & 0.6770 & 1.52260 & 152.2604 & 4.3310 & 3.7203 & $5(7$ to 8$)$ \\
\hline T5 & 2,3 & 5 & 0.4860 & 0.43772 & 43.7716 & 2.5070 & 2.0115 & $3(5$ to 7$)$ \\
\hline T6 & 1 & 8 & 1.2410 & 1.24089 & 124.0892 & 4.4390 & 2.2023 & $5(7$ to 8$)$ \\
\hline T7 & $1,2,3$ & 5,8 & 0.7380 & 1.40208 & 140.2082 & 4.4523 & 3.2861 & $3(5$ to 7$)$ \\
\hline T8 & 2,3 & 6 & 0.6010 & 0.75099 & 75.0992 & 2.9377 & 3.0173 & $3(5$ to 7$)$ \\
\hline T9 & 1,2 & 8 & 0.5950 & 0.59529 & 59.5292 & 2.6632 & 1.7187 & $5(7$ to 8$)$ \\
\hline T10 & 1,2 & 5,6 & 0.7450 & 1.60236 & 160.2364 & 4.8511 & 4.2759 & $3(5$ to 7$)$ \\
\hline \multicolumn{9}{|c|}{ Voltage Constrained Transactions } \\
\hline T11 & 1 & 6 & 0.9700 & 1.21272 & 121.2717 & 4.0264 & 3.0622 & bus-6 \\
\hline T12 & 1,3 & 6 & 0.9320 & 1.16474 & 116.4743 & 3.9116 & 3.1138 & bus-6 \\
\hline T13 & $1,2,3$ & $5,6,8$ & 0.7140 & 2.24809 & 224.8094 & 5.9844 & 4.8829 & bus-6 \\
\hline
\end{tabular}

TABLE III

ENhanced ATC VAlues with TCSC USING $P I-P S O$ FOR IT \& DN

\begin{tabular}{|c|c|c|c|c|c|}
\hline \multirow{2}{*}{$\begin{array}{c}\text { Trans } \\
\text { ID }\end{array}$} & \multirow{2}{*}{$\begin{array}{c}\text { ATC } \\
{[\mathrm{MW}]}\end{array}$} & \multirow{2}{*}{$\begin{array}{l}P_{\text {loss }} \\
\text { [MW] }\end{array}$} & \multirow{2}{*}{$\begin{array}{c}V_{D} \\
\text { [p.u.] }\end{array}$} & \multicolumn{2}{|c|}{ TCSC Solution } \\
\hline & & & & Line No. & \% Comp \\
\hline T1 & 154.5033 & 6.7954 & 3.4577 & $8(9$ to 6$)$ & 80 \\
\hline T2 & 153.4515 & 4.7291 & 3.044 & $3(5$ to 7$)$ & 49.2712 \\
\hline T3 & 172.1144 & 5.0027 & 3.9008 & $8(9$ to 6$)$ & 75.5499 \\
\hline T4 & 178.2661 & 5.0092 & 4.2383 & $3(5$ to 7$)$ & 44.6538 \\
\hline T5 & 64.4571 & 3.052 & 2.3949 & $8(9$ to 6$)$ & 80 \\
\hline T6 & 153.3719 & 5.5736 & 2.3356 & $9(6$ to 4$)$ & 80 \\
\hline T7 & 151.2495 & 4.7096 & 3.2706 & $5(7$ to 8$)$ & 53.965 \\
\hline T8 & 101.3858 & 3.5028 & 3.3194 & $8(9$ to 6$)$ & 56.4783 \\
\hline T9 & 79.304 & 3.1254 & 2.1354 & $3(5$ to 7$)$ & 68.1384 \\
\hline T10 & 171.4634 & 5.0718 & 4.1904 & $8(9$ to 6$)$ & 34.4068 \\
\hline
\end{tabular}

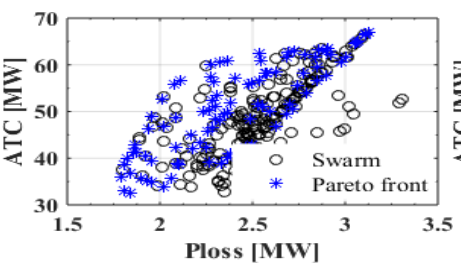

(a)

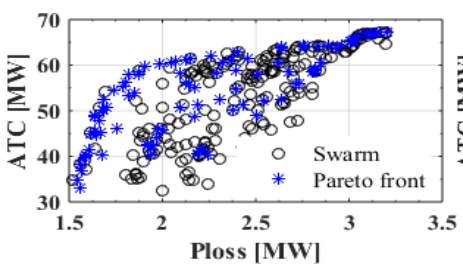

(c)

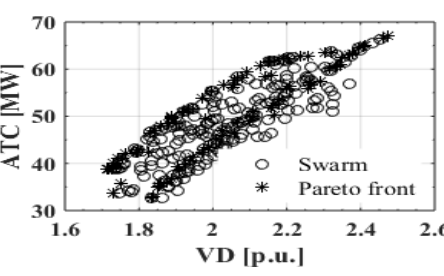

(b)

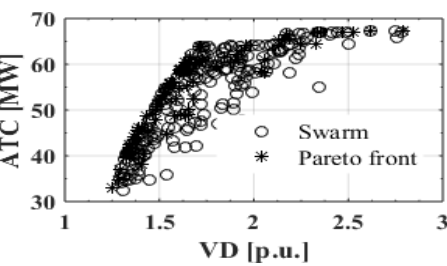

(d)
Fig. 8. Slices of Pareto plot for transaction T3 under TCSC-DG. (a) ATC versus $P_{\text {loss }}\left(T C S C-D G_{P V}\right)$ (b) ATC versus $V_{D}\left(T C S C-D G_{P V}\right)$ (c) ATC versus $P_{\text {loss }}\left(T C S C-D G_{P Q}\right)(\mathrm{d})$ ATC versus $V_{D}$ $\left(T C S C-D G_{P Q}\right)$

$V_{D}$, respectively. In the case of $T C S C-D G_{P V}$, from Figs. $7 \mathrm{a}$ and $7 \mathrm{c}$, it was observed that the Pareto front peaks with ATC, Ploss and $V_{D}$ values around $168 \mathrm{MW}, 6.2 \mathrm{MW}$ and 3.8 p.u. as against $154.5 \mathrm{MW}, 6.7 \mathrm{MW}$ and 3.5 p.u respectively. These improvements are attributable to DSO's resources, such as DG in coordination with the TSO's TCSC.
For comparison and deeper insight into the non-dominated solutions, a two-level criterion is adopted to select one nondominated solution as the optimum compromise of the three objectives. In the first level, the ATC enhancement is given priority, such that all solutions with higher ATC compared to TCSC only constitute the optimum solution. The second level criterion is based on the concept of dominance, and a member of the non-dominated solution with at least two superior objectives compared to TCSC only equally constitute the optimum solution. Finally, from the list of the optimum solutions, a non-dominated solution is selected as the optimal solution by applying the first level criteria again. Subsequently, for transactions T1 to T10, Tables IV and V gives the objective terms and the corresponding solutions for $T C S C-D G_{P V}$ and $T C S C-D G_{P Q}$ coordination, respectively.

For Transaction T1, from Table V, Figs. 7c and 7d, it is seen that the PQ model of DG, in coordination with TCSC (as in $T C S C-D G_{P Q}$ ), provide superior ATC values compared with the PV model of DG, which is depicted by Table IV and Figs. $7 \mathrm{a}$ and $7 \mathrm{~b}$. Also, for the ATC versus Ploss, such as illustrated in Figs. 8c and 8d, the Pareto slices indicate that at some maximum ATC, the slope of the Pareto front approaches zero, implying that additional power losses are incurred without a corresponding enhancement in ATC.

An important event considered in power systems planning and operations is the outage of the TSO's equipment, such as the transmission line. Therefore, in the TSO managed model, a single line outage $(N-1)$ contingency can illustrate the impacts of TSO's contingency on the integrated Transmission and Distribution Networks. Consequently, Table VI gives the result of $(N-1)$ contingency based on equation (37). From the topology of Fig. 4, at the transmission section, the transformer branch outages are termed Invalid in Table VI, since it also results in the outage of a generator; while the unfeasible term refers to line outages that cause singularity and hence nonconvergence of the load flow at the base case. In Table VI, $P I_{S}, P I_{V 1}$ and $P I_{V 2}$ are the apparent power version of the performance index, and the two voltage variant measurements of line outage performance index described by equation (37). The ranks of the outage lines based on the composite severity indices $P I_{S-V 1}, P I_{S-V 2}$ and $P I_{S}$ are shown in boldface. 
TABLE IV

$T C S C-D G P V$ COORDINATION SOLUTION FOR T1 TO T10

\begin{tabular}{|c|c|c|c|c|c|c|c|c|}
\hline \multirow{2}{*}{$\begin{array}{c}\text { Trans } \\
\text { ID }\end{array}$} & \multicolumn{2}{|r|}{ ATC [MW] } & \multicolumn{6}{|c|}{$T C S C-D G_{P V}$ Solution } \\
\hline & TCSC & $T C S C-D G_{P V}$ & Ploss $[M W]$ & $V_{D}[p . u]$. & Line No. & \% Comp. & Node No. & $P_{S} i z e[\mathrm{MW}]$ \\
\hline T1 & 154.503 & 168.8304 & 6.206 & 3.8241 & $8(9$ to 6$)$ & 80 & 21 & 3.9664 \\
\hline T2 & 153.452 & 153.5067 & 4.7252 & 3.0241 & $3(5$ to 7$)$ & 48.9181 & 10 & 8.7171 \\
\hline T3 & 172.114 & 172.2701 & 4.8214 & 3.8249 & $8(9$ to 6$)$ & 80 & 49 & 10.2293 \\
\hline $\mathrm{T} 4$ & 178.266 & 178.8987 & 4.999 & 4.1679 & $3(5$ to 7$)$ & 25.6021 & 28 & 21.5 \\
\hline T5 & 64.4571 & 63.5931 & 2.9089 & 2.3187 & $8(9$ to 6$)$ & 80 & 31 & 6.3847 \\
\hline T6 & 153.372 & 168.3154 & 4.7358 & 2.3954 & $9(6$ to 4$)$ & 80 & 50 & 21.5 \\
\hline $\mathrm{T} 7$ & 151.25 & 151.6302 & 4.6989 & 3.2171 & $5(7$ to 8$)$ & 80 & 42 & 11.9087 \\
\hline $\mathrm{T} 8$ & 101.386 & 101.5266 & 3.5288 & 3.11 & $8(9$ to 6$)$ & 69.1184 & 48 & 21.5 \\
\hline T9 & 79.304 & 79.6278 & 2.9211 & 1.9826 & $3(5$ to 7$)$ & 62.1141 & 36 & 14.7665 \\
\hline T10 & 171.463 & 169.5974 & 5.0629 & 4.1745 & $5(7$ to 8$)$ & 68.3549 & 26 & 14.2134 \\
\hline
\end{tabular}

TABLE V

$T C S C-D G P Q$ COORDINATION SOLUTION FOR T1 TO T10

\begin{tabular}{|c|c|c|c|c|c|c|c|c|c|}
\hline $\begin{array}{c}\text { Trans } \\
\text { ID }\end{array}$ & \multicolumn{2}{|r|}{ ATC [MW] } & \multicolumn{6}{|c|}{$T C S C-D G_{P Q}$ Solution } & $Q_{S} i z e$ [MVAR] \\
\hline T2 & 153.452 & 155.3124 & 4.6795 & 2.4445 & 3 & 46.5784 & 56 & 0 & 13 \\
\hline T3 & 172.114 & 174.1671 & 4.5908 & 3.3141 & 8 & 68.634 & 18 & 0 & 12.9518 \\
\hline T5 & 64.4571 & 66.5036 & 3.0491 & 2.1733 & 8 & 80 & 11 & 19.7611 & 12.7953 \\
\hline T6 & 153.372 & 181.9170 & 3.6233 & 1.5008 & 9 & 80 & 50 & 21.5 & 13 \\
\hline $\mathrm{T} 7$ & 151.25 & 153.7433 & 4.685 & 2.7673 & 5 & 52.0642 & 56 & 0.2591 & 12.9781 \\
\hline $\mathrm{T} 10$ & 171.463 & 173.9668 & 4.8871 & 3.8261 & 5 & 44.2909 & 14 & 0 & 10.9326 \\
\hline
\end{tabular}

From each severity indices shown in Table VI, a list of severe and credible contingencies considered are obtained.

The ATC enhancement with TCSC was obtained under the credible $(N-1)$ outage contingencies for all power transfer transactions in Table II. Fig. 9 depicts the impacts of various $(N-1)$ contingencies on the power transfer transactions outlined in Table II. From Figs. 9a to 9i observed that the line $9(6$ to 4$)$ outage results in zero ATC, which is also consistent with the contingency status of Table VI caused by the singularity of the base case load flow solution. However, with the optimal deployment of TCSC, for all the transactions, Fig. 9 also depicts enhancement of the ATC above zero under line $9(6$ to 4$)$ outage.

Furthermore, among the credible contingencies, line 6(8 to 9) outage results in the least ATC value with and without
TCSC. Generally, TCSC enhances ATC above base case under all contingencies considered.

Additionally, while the impacts of TSO's contingencies have been illustrated in Fig. 9, DSO resources such as DG reduces the severity of the $(N-1)$ contingency, which is a vital feature of the TSO managed model. Consequently, Figs. 10 to Fig. 12 depicts the Pareto front slices of ATC versus Ploss and ATC versus $V_{D}$ with $T C S C-D G$ coordination under the credible contingencies.

From Figs. 10 to 12, compared with TCSC only under contingencies, the ATC, Ploss and $V_{D}$ were further improved with $T C S C-D G$ coordination. Similar to the cases without contingencies, comparing Figs. 10a and 10c, Figs. 10b and $10 \mathrm{~d}$, the $T C S C-D G_{P Q}$ under $(N-1)$ obtained superior ATC values than $T C S C-D G_{P V}$. Similar deduction is made

TABLE VI

$T C S C-D G P Q$ COORDINATION SOLUTION FOR T1 TO T10

\begin{tabular}{|c|c|c|c|c|c|c|c|c|c|}
\hline $\begin{array}{l}\text { Line No. } \\
\text { (bus i to j) }\end{array}$ & $\begin{array}{l}\text { Cont. } \\
\text { Status }\end{array}$ & $P I_{S}$ & $\begin{array}{l}P I_{S} \\
\text { Rank }\end{array}$ & $P I_{S-V 1}$ & $P I_{S-V 2}$ & $P I_{S-V 1}$ & $\begin{array}{c}P I_{S-V 2} \\
\text { Rank }\end{array}$ & $P I_{S-V 1}$ & $\begin{array}{c}P I_{S-V 2} \\
\text { Rank }\end{array}$ \\
\hline $1(1$ to 4$)$ & Invalid & $\mathrm{NaN}$ & void & $\mathrm{NaN}$ & $\mathrm{NaN}$ & $\mathrm{NaN}$ & void & $\mathrm{NaN}$ & void \\
\hline $2(4$ to 5$)$ & feasible & 0.6302 & 6 & 0.265 & 0 & 0.8952 & 5 & 0.6302 & 6 \\
\hline $3(5$ to 7$)$ & unfeasible & 1.1672 & 1 & 0.1808 & 0 & 1.3481 & 2 & 1.1672 & 1 \\
\hline $4(2$ to 7$)$ & Invalid & $\mathrm{NaN}$ & void & $\mathrm{NaN}$ & $\mathrm{NaN}$ & $\mathrm{NaN}$ & void & $\mathrm{NaN}$ & void \\
\hline $5(7$ to 8$)$ & unfeasible & 1.0961 & 2 & 0.204 & 0 & 1.3001 & 4 & 1.0961 & 3 \\
\hline $6(8$ to 9$)$ & feasible & 0.6526 & 5 & 0.085 & 0 & 0.7376 & 6 & 0.6526 & 5 \\
\hline $7(9$ to 3$)$ & Invalid & $\mathrm{NaN}$ & void & $\mathrm{NaN}$ & $\mathrm{NaN}$ & $\mathrm{NaN}$ & void & $\mathrm{NaN}$ & void \\
\hline $8(9$ to 6$)$ & feasible & 0.957 & 4 & 0.3675 & 0 & 1.3245 & 3 & 0.957 & 4 \\
\hline $9(6$ to 4$)$ & unfeasible & 1.0373 & 3 & 1.4192 & 0.074 & 2.4565 & 1 & 1.1113 & 2 \\
\hline \multicolumn{2}{|c|}{$\begin{array}{c}\text { Severe } \\
\text { Contingencies }\end{array}$} & \multicolumn{2}{|c|}{$\begin{array}{l}3(5 \text { to } 7), \\
5(7 \text { to } 8), \\
9(6 \text { to } 4)\end{array}$} & $\begin{array}{l}9(6 \text { to } 4), \\
8(9 \text { to } 6), \\
2(4 \text { to } 5)\end{array}$ & $9(6$ to 4$)$ & \multicolumn{2}{|c|}{$\begin{array}{l}9(6 \text { to } 4), \\
3(5 \text { to } 7), \\
8(9 \text { to } 6)\end{array}$} & \multicolumn{2}{|c|}{$\begin{array}{l}3(5 \text { to } 7), \\
9(6 \text { to } 4), \\
5(7 \text { to } 8)\end{array}$} \\
\hline \multicolumn{2}{|c|}{ Credible Contingencies } & \multicolumn{8}{|c|}{$2(4$ to 5$), 6(8$ to 9$), 8(9$ to 6$)$} \\
\hline
\end{tabular}




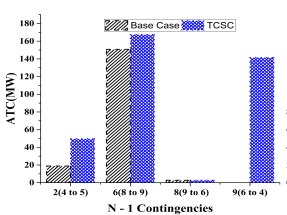

(a)

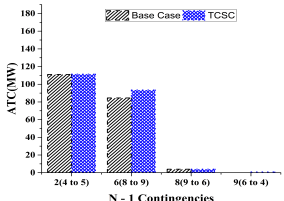

(d)

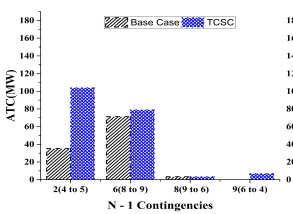

(g)

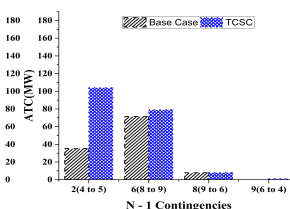

(b)

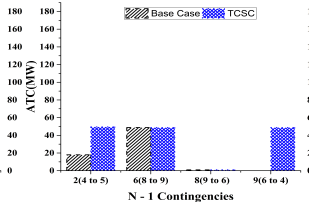

(e)

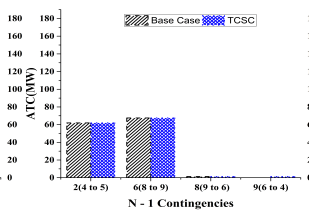

(h)

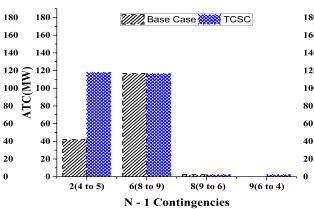

(c)

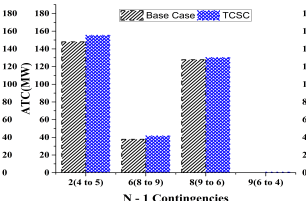

(f)

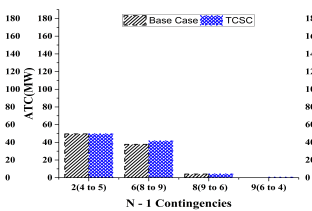

(i)

Fig. 9. Impacts of $(N-1)$ Contingencies on power transfers: (a)T1 under $(N-1)$ Contingencies (b)T2 under $(N-1)$ Contingencies (c)T3 under $(N-1)$ Contingencies (d)T4 under $(N-1)$ Contingencies (e)T5 under $(N-1)$ Contingencies (f)T6 under $(N-1)$ Contingencies (g)T7 under $(N-1)$ Contingencies (h)T8 under $(N-1)$ Contingencies (i)T9 under $(N-1)$ Contingencies (j).

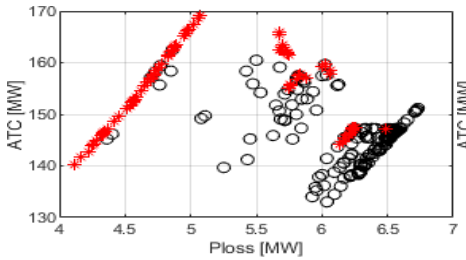

(a)

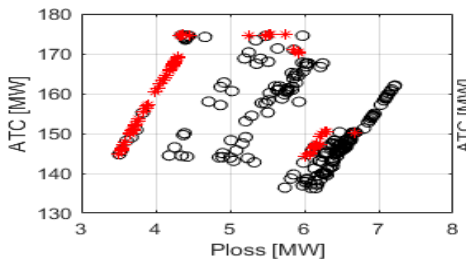

(c)

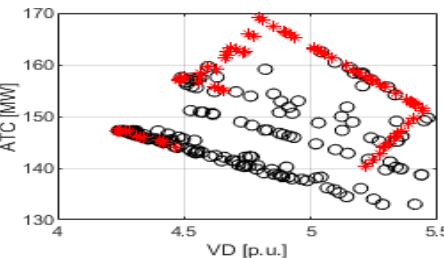

(b)

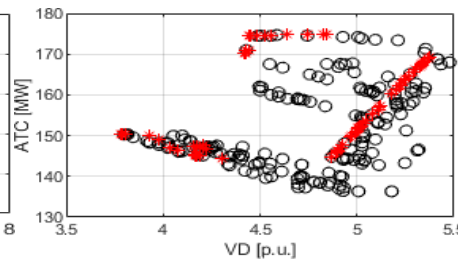

(d)

Fig. 10. Slices of Pareto plot for T1 under line 6(8 to 9) outage: (a)ATC Versus Ploss $\left(T C S C-D G P_{P V}\right)$ (b)ATC Versus VD (TCSC-DGP $\left.P_{P V}\right)$ (c)ATC Versus Ploss $\left(T C S C-D G P_{P Q}\right)(\mathrm{d}) \mathrm{ATC}$ Versus VD $\left(T C S C-D G P_{P Q}\right)$

with Figs. 12. The Paretor front shapes are similar and specific to transfer directions.

\section{CONCLUSION}

This paper demonstrates the TSO - DSO coordination through a TSO managed model. The developed approach which allows for multiple objectives, account for both the TSO and DSO performance indices. While the various contingencies considered reduces the ATC values, improvements in the ATC, Ploss and $V_{D}$ were obtained by the deployment

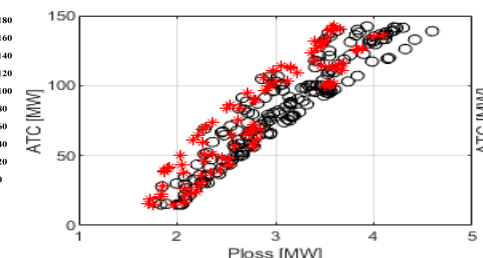

(a)

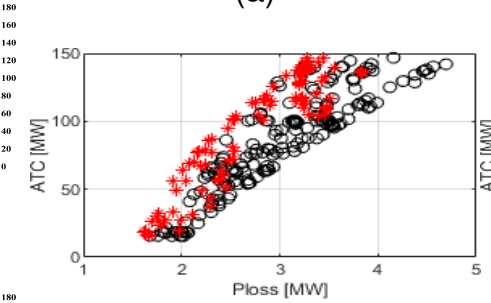

(c)

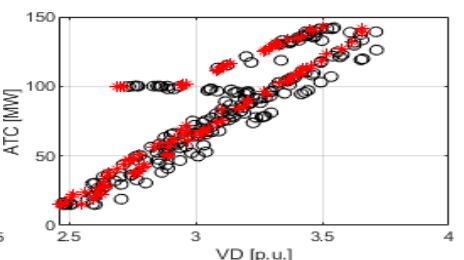

(b)

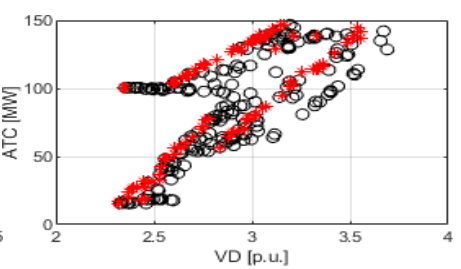

(d)
Fig. 11. Slices of Pareto plot for T2 under line 2(4 to 5) outage: (a)ATC Versus Ploss $\left(T C S C-D G P_{P V}\right)$ (b)ATC Versus VD $\left(T C S C-D G P_{P V}\right)$ (c)ATC 20 Versus Ploss $\left(T C S C-D G P_{P Q}\right)(\mathrm{d}) \mathrm{ATC}$ Versus VD $\left(T C S C-D G P_{P Q}\right)$

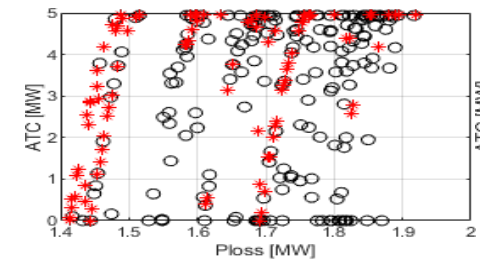

(a)

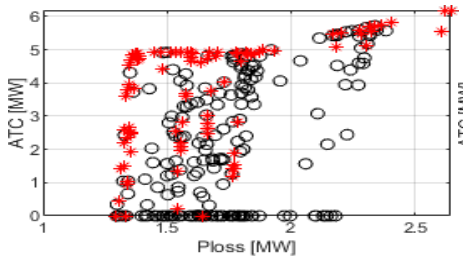

(c)

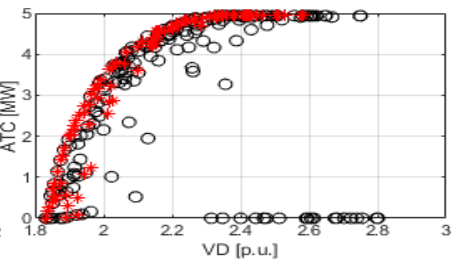

(b)

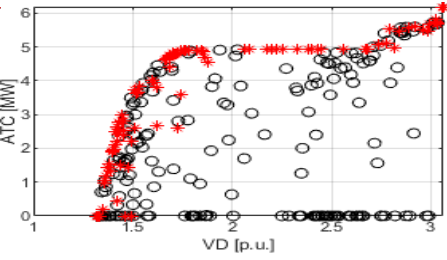

(d)
Fig. 12. Slices of Pareto plot for T4 under line $8(9$ to 6$)$ outage: (a)ATC Versus Ploss $\left(T C S C-D G P_{P V}\right)$ (b)ATC Versus VD $\left(T C S C-D G P_{P V}\right)$ (c)ATC Versus Ploss $\left(T C S C-D G P_{P Q}\right)(\mathrm{d}) \mathrm{ATC}$ Versus VD $\left(T C S C-D G P_{P Q}\right)$

of DG as a DSOs resource in coordination with the TCSC under single line $(N-1)$ outage contingencies. The Pareto front plots provide deeper insight into the correlation between ATC against Ploss and ATC against $V_{D}$. Compared to the PV model of DG, the PQ model aside the improvement in ATC, also reduces the power losses. This improvement is attributable to the reactive power supply by the PQ model of DG. The parabolic like shape of the Pareto front indicate that after some maximum ATC values, additional power losses are incurred without a corresponding improvement in the ATC, hence power transfer are not implemented beyond such point.

\section{REFERENCES}

[1] M. R. Sindhu, M. Jisma, P. Maya, P. Krishnapriya, and M. Vivek Mohan, Optimal Placement and Sizing of Harmonic and Reactive Compensators in Interconnected Systems, in INDICON 2018 - 15th IEEE India Council International Conference, 2018, pp. 1-6. 
[2] G. Ramesh and V. R. Babu, Combined FACTS and Microgrid-Based, in Advances in Electrical and Computer Technologies, Lecture Notes in Electrical Engineering 711, Springer Singapore, 2021, pp. 106-1073.

[3] S. Santhanalakshmi and S. Dhivya, Enhancement of power transfer ability in transmission and distribution line using TCSC, Malaya J. Mat., vol. S, no. 2, pp. 3243-3247, 2020.

[4] A. Singh and A. K. Bohre, Congestion management of System by optimal placement of TCSC inacontingency condition, J. Indian Chem. Soc, WEES 2020 Spec. Issue, vol. 97, no. October(B), pp. 1-7, 2020.

[5] A. A. Sadiq, S. S. Adamu, and M. Buhari, Optimal distributed generation planning in distribution networks: A comparison of transmission network models with FACTS, Eng. Sci. Technol. an Int. J., vol. 22, no. 1, pp. $33-46,2019$.

[6] S. Gumpu, B. Pamulaparthy, and A. Sharma, Review of Congestion Management Methods from Conventional to Smart Grid Scenario, Int. J. Emerg. Electr. Power Syst., vol. 20, no. 3, pp. 1-24, 2019.

[7] A. A. L. Ahmad and R. Sirjani, Optimal placement and sizing of multitype FACTS devices in power systems using metaheuristic optimisation techniques: An updated review Cumulative Gravitational Search algorithm Opposition Gravitational Search algorithm, Ain Shams Eng. J., vol. 11, no. 3, pp. 611-628, 2020.

[8] C. Doddala and V. Suryanarayanareddy, Transmission Line Congestion Management using Hybrid Fish-Bee Algorithm with IPFC, Int. Res. J. Eng. Technol., vol. 06, no. 09, pp. 2120-2126, 2019.

[9] A. A. Sadiq, S. S. Adamu, I. Ndakara, and L. Yusuf, Impact of SVC and DG Coordination on Voltage Constrained Available Transfer Capability, in 3rd International Engineering Conference (IEC 2019), 2019, no. Iec, pp. 615-619.

[10] A. A. Sadiq, S. S. Adamu, and M. Buhari, Available transfer capability enhancement with FACTS using hybrid PI-PSO, Turkish J. Electr. Eng. Comput. Sci., vol. 27, no. 4, pp. 2881-2897, 2019.

[11] A. A. Sadiq, M. Buhari, S. S. Adamu, and H. Musa, Coordination of multi-type FACTS for available transfer capability enhancement using PI-PSO, IET Gener. Transm. Distrib., vol. 14, no. 21, 2020.

[12] A. Fughar, M. N. Nwohu, A. A. Sadiq, and J. G. Ambafi, Voltage Profile Enhancement of the Nigerian North-East 330kV Power Network Using STATCOM, Int. J. Adv. Res. Sci. Eng. Technol., vol. 2, no. 1, 2015.

[13] S. Rakoevi, M. alasan, and S. H. E. Abdel Aleem, Smart and coordinated allocation of static VAR compensators, shunt capacitors and distributed generators in power systems toward power loss minimization, Energy Sources, Part A Recover. Util. Environ. Eff., vol. 00, no. 00, pp. 1-19, 2021.

[14] T. George, A. R. Youssef, and S. Kamel, Optimal Allocation of DGs and TCSC in Radial Networks Using Ant Lion Optimizer, in 2018 20th International Middle East Power Systems Conference, MEPCON 2018 Proceedings, 2019, pp. 1092-1097.

[15] H. Saberi, S. Mehraeen, and B. Wang, Stability Improvement of Microgrids Using a Novel Reduced UPFC Structure via Nonlinear Optimal Control, in 2018 IEEE Applied Power Electronics Conference and Exposition (APEC), 2018, pp. 3294-3300.

[16] M. Pandya and J. G. Jamnani, Transient stability assessment by coordinated control of SVC and TCSC with particle swarm optimization, Int. J. Eng. Adv. Technol., vol. 9, no. 1, pp. 2506-2510, 2019.

[17] B. Singh, V. Mukherjee, and P. Tiwari, GA-based optimization for optimally placed and properly coordinated control of distributed generations and Static Var Compensator in distribution networks, Energy Reports, vol. 5, pp. 926-959, 2019.

[18] M. Shafiul Alam, F. S. Al-Ismail, A. Salem, and M. A. Abido, Highlevel penetration of renewable energy sources into grid utility: Challenges and solutions, IEEE Access, vol. 8, pp. 190277-190299, 2020.

[19] J. A. P. Lopes, N. Hatziargyriou, J. Mutale, P. Djapic, and N. Jenkins, Integrating distributed generation into electric power systems: A review of drivers, challenges and opportunities, Electr. Power Syst. Res., vol. 77, no. 9, pp. 1189-1203, 2007.

[20] Y. Zhang, Y. Xu, H. Yang, and Y. Z. Dong, Voltage regulationoriented co-planning of distributed generation and battery storage in active distribution networks, Electr. Power Energy Syst., vol. 105, pp. 79-88, 2019.

[21] O. A. C. De Koster and J. A. Domnguez-Navarro, Multi-objective tabu search for the location and sizing of multiple types of FACTS and DG in electrical networks, Energies, vol. 13, no. 11, 2020.

[22] F. Ugranli and E. Karatepe, Coordinated TCSC Allocation and Network Reinforcements Planning with Wind Power, IEEE Trans. Sustain. Energy, vol. 8, no. 4, pp. 1694-1705, 2017.

[23] V. Kohan, Z. Conka, and M. Kolcun, Impact of TCSC on generator operation, in CANDO-EPE 2020 - Proceedings, IEEE 3rd International
Conference and Workshop in Obuda on Electrical and Power Engineering, pp. 131-136.

[24] A. G. Givisiez, K. Petrou, and L. F. Ochoa, A Review on TSO-DSO Coordination Models and Solution Techniques, Electr. Power Syst. Res., vol. 189,2020

[25] S. Massucco, P. Pongiglione, F. Silvestro, M. Paolone, and F. Sossan, Siting and Sizing of Energy Storage Systems: Towards a Unified Approach for Transmission and Distribution System Operators for Reserve Provision and Grid Support, in 21st Power Systems Computation ConferencePower Systems Computation Conference, 2020, pp. 1-8.

[26] H. Gerard, E. I. Rivero Puente, and D. Six, Coordination between transmission and distribution system operators in the electricity sector: A conceptual framework, Util. Policy, vol. 50, pp. 40-48, 2018.

[27] A. Hermann, T. V. Jensen, J. stergaard, and J. Kazempour, A Complementarity Model for Electric Power Transmission-Distribution Coordination Under Uncertainty, Eur. J. Oper. Res., 2021.

[28] M. Bolfek and T. Capuder, An analysis of optimal power flow based formulations regarding DSO-TSO flexibility provision, Int. J. Electr. Power Energy Syst., vol. 131, no. January, p. 106-935, 2021.

[29] M. A. El-Meligy, M. Sharaf, and A. T. Soliman, A coordinated scheme for transmission and distribution expansion planning: A Tri-level approach, Electr. Power Syst. Res., vol. 196, no. April, 2021.

[30] S. Ghaedi, B. Tousi, M. Abbasi, and M. Alilou, Optimal Placement and Sizing of TCSC for Improving the Voltage and Economic Indices of System with Stochastic Load Model, J. Circuits, Syst. Comput., vol. 29 , no. 13, pp. 1-21, 2020

[31] S. Galvani, B. Mohammadi-Ivatloo, M. Nazari-Heris, and S. RezaeianMarjani, Optimal allocation of static synchronous series compensator (SSSC) in wind-integrated power system considering predictability, Electr. Power Syst. Res., vol. 191, no. September 2020, p. 106-871, 2021.

[32] A. G. Givisiez, K. Petrou, and L. F. Ochoa, A Review on TSO-DSO Coordination Models and Solution Techniques, Electr. Power Syst. Res., vol. 189, no. October 2019, p. 106-659, 2020.

[33] V. R. Srinivasa V and R. Srinivasa R, Comparison of Various Methods for Optimal Placement of FACTS Devices, in International Conference on Smart Electric Grid (ISEG), 2014, 2014, pp. 1-7.

[34] B. Mahdad and K. Srairi, Adaptive Differential Search Algorithm for Optimal Location of Distributed Generation in the presence of SVC for Power Loss Reduction in Distribution System, Eng. Sci. Technol. an Int. J., vol. 19, no. 3, pp. 1266-1282, 2016.

[35] S. Jahan and A. M. Mannan, Voltage Stability Analysis of a 16bus Distribution Network Based on Voltage Sensitivity Factor, Int. J. Multidiscip. Sci. Energieering, vol. 5, no. 4, pp. 1-5, 2014.

[36] A. S. . Ogunjuyigbe, T. R. Ayodele, and O. . Akinola, Impact of Distributed Generators on the Power Loss and Voltage Profile of SubTransmission Network, J. Electr. Syst. Inf. Technol., vol. 3, no. 1, pp. 94-107, 2016.

[37] C. Ma, P. Kaufmann, J. C. Tbermann, and M. Braun, Optimal Generation Dispatch of Distributed Generators Considering Fair Contribution to Grid Voltage Control, Renew. Energy, vol. 87, pp. 946-953, 2016.

[38] N. S. Vadivoo and S. M. R. Slochanal, Distribution System Restoration Using Genetic Algorithm with Distributed Generation, Mod. Appl. Sci., vol. 3, no. 4, pp. 98-110, 2009.

[39] N. G. A. Hemdan and M. Kurrat, Efficient Integration of Distributed Generation for Meeting the Increased Load Demand, Int. J. Electr. Power Energy Syst., vol. 33, no. 9, pp. 1572-1583, 2011.

[40] E. S. Ali, S. M. A. Elazim, and A. Y. Abdelaziz, Ant Lion Optimization Algorithm for Optimal Location and Sizing of Renewable Distributed Generations, Renew. Energy, vol. 101, pp. 1311-1324, 2017.

[41] S. A. Chithradevi, L. Lakshminarasimman, and R. Balamurugan, Stud Krill Herd Algorithm for Multiple DG Placement and Sizing in a Radia Distribution System, Eng. Sci. Technol. an Int. J., vol. 20, no. 2, pp. 748-759, 2017

[42] A. A. Hassan, F. H. Fahmy, A. A. Nafeh, and M. A. Abuelmagd, Genetic Single Objective Optimisation for Sizing and Allocation of Renewable DG Systems, Int. J. Sustain. Energy, vol. 6451, no. October, pp. 1-18, 2015.

[43] M. Balasubbareddy, S. Sivanagaraju, and C. Venkata, A Non-Dominated Sorting Hybrid Cuckoo Search Algorithm for Multi-Objective Optimization in the Presence of FACTS Devices, Russ. Electr. Eng., vol. 88, no. 1, pp. 44-53, 2017.

[44] C. a Canizares, A. Berizzi, and P. Marannino, Using FACTS Controllers to Maximize Available Transfer Capability, in Proceedings of the Bulk Power Systems Dynamics and Control IVRestructuring, 1998, pp. 633641. 